\title{
Mobilidade de contaminantes em solos arenosos após a aplicação de águas residuárias tratadas produzidas em indústria siderúrgica
}

\author{
Contaminant mobility in sandy soils after application \\ of treated wastewater produced in the steel industry
}

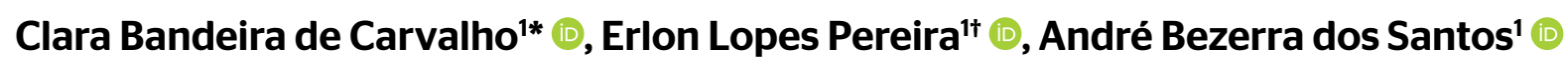

\section{RESUMO}

Este trabalho teve como objetivo realizar um estudo de modelagem da dispersão de contaminantes no solo com águas residuárias produzidas e tratadas em uma indústria siderúrgica. Para isso, foram realizados ensaios de coluna de lixiviação utilizando amostras de solo coletadas nas áreas dentro da indústria onde aconteceria o reúso das águas residuárias tratadas nas estações de tratamento da própria siderúrgica. Com base nos ensaios, foram geradas curvas de eluição (breakthrough curves), para análise da mobilidade dos contaminantes no solo, e obtidos os parâmetros de transporte (coeficiente de dispersão, retardamento e dispersividade). As águas residuárias produzidas na siderúrgica apresentam baixas concentrações de metais pesados após o tratamento realizado, sendo apenas o ferro e o zinco, contaminantes de maior preocupação para a disposição no solo. Os solos analisados, com elevado percentual de areia, demonstraram ineficiência na retenção dos contaminantes presentes, aumentando os riscos de contaminação da água subterrânea. Conclui-se que, para a indústria siderúrgica realizar o reúso não potável das águas residuárias, deve-se associar este a técnicas de manejo e conservação do solo que aumentem a capacidade do solo em adsorver contaminantes, ou de impermeabilização na área de resfriamento de placas. Palavras-chave: disposição no solo; ensaios de colunas de lixiviação; parâmetros de transporte; reúso; transporte de contaminantes.

\begin{abstract}
This research aimed to carry out a modeling study on the dispersion of contaminants in the soil with wastewater produced and treated in a steel industry. For this purpose, column leaching tests were performed using soil samples collected in areas inside the industry where the reuse of treated wastewater would occur. Based on the tests, elution curves (breakthrough curves) were generated to analyze the mobility of contaminants in the soil, and transport parameters were obtained (dispersion coefficient, delay, and dispersivity). The wastewater produced in the steelworks has low concentrations of heavy metals after the wastewater treatment is carried out, with only iron and zinc posing a risk for wastewater disposal. The analyzed soils, with a high percentage of sand, showed a low retention capacity for the contaminants present, increasing the risks of groundwater contamination. Therefore, the non-potable reuse of treated wastewater is possible in the steel industry, but it must be associated with soil management and conservation techniques that increase the capacity of the soil to adsorb its contaminants or the impermeabilization in the area of plate cooling.
\end{abstract}

Keywords: soil disposal; column leaching tests; transport parameters; reuse; contaminants' transport.

\section{INTRODUÇÃO}

As indústrias siderúrgicas utilizam elevado volume de água em processos de resfriamento, lavagem de poeira e descalcificação, sendo uma pequena parcela consumida e o restante descartado para estações de tratamento (COLLA et al., 2017). Em um cenário de escassez hídrica, alternativas de gestão têm sido adotadas, visando à redução do consumo de água bem como dos impactos ambientais acarretados pela disposição inadequada de efluentes. Nesse sentido, o reúso de águas residuárias (AR) configura-se como importante ferramenta de gestão sustentável (TORETTA et al., 2020).

Além das aplicações do reúso de água dentro do processo produtivo de uma indústria siderúrgica, existem também opções relacionadas à manutenção

'Universidade Federal do Ceará - Fortaleza (CE), Brasil.

tin memoriam

*Autor correspondente: andre23@ufc.br

Conflitos de interesse: os autores declaram não haver conflitos de interesse

Financiamento: nenhum.

Recebido: 25/09/202O - Aceito: 05/O4/2O21 - Reg. ABES: 20200339 
do empreendimento, como lavagem de pisos, irrigação de áreas verdes e resfriamento da escória. Algumas das modalidades envolvem o lançamento do efluente no solo, gerando riscos de contaminação deste pelo acúmulo de compostos, além de contaminação das águas subterrâneas pela lixiviação de solutos (ANDRADE et al., 2018), alteração das características físico-químicas do solo e diminuição de sua fertilidade. Em uma siderúrgica, a contaminação decorrente do lançamento da água residuária tratada pode se dar principalmente pela presença de metais pesados e outros íons, a depender da composição da água utilizada.

Os íons presentes no solo e os lançados podem lixiviar para camadas mais profundas do solo, podem ser absorvidos pelos vegetais presentes ou precipitados, caso estejam com concentração maior do que sua capacidade de solubilidade ou em altos valores de pH (BASSO \& KIANG, 2017). O solo tem grande capacidade de retenção dos metais pesados. Entretanto, quando essa capacidade é ultrapassada, pode levar a processos de carreamento e poluição das águas subterrâneas. O deslocamento dos solutos no solo é influenciado pelas características do líquido percolante, pelas propriedades físico-químicas do solo bem como pelas condições ambientais do meio que influenciam os parâmetros de transporte dos solutos (OLIVEIRA et al., 2010; SILVA et al., 2012).

O estudo do transporte de solutos no solo é uma importante ferramenta na determinação de impactos ambientais e de riscos de contaminação do meio ambiente, pois, em conjunto com o uso de modelos matemáticos, podem ser conhecidas as características de íons específicos, como a maneira como interagem com os componentes do meio e sua movimentação e persistência no solo, possibilitando o entendimento quanto à mobilidade de substâncias químicas no solo (BASSO \& KIANG, 2017).

Estudos têm sido conduzidos para avaliar a mobilidade de solutos no solo utilizando ensaios de deslocamento em colunas de solo associados a modelos matemáticos (OLIVEIRA et al., 2010; MATOS et al., 2013; OLIVEIRA et al., 2013; BASSO \& KIANG, 2017; ANDRADE et al., 2018), o que possibilita entender o comportamento dos solutos no meio poroso. Estudos sobre a movimentação de metais estão voltados para resíduos sólidos da construção civil (MOREIRA et al., 2010) e para resíduos sólidos urbanos (OLIVEIRA et al., 2013), sendo utilizados na maioria, soluções percoladoras artificiais cuja concentração dos contaminantes é estabelecida previamente. Entretanto, estudos de modelagem para AR provenientes das estações de tratamento, especialmente com fins de reúso em escala real, são raros na literatura.

Parâmetros utilizados para conhecer a maneira como os solutos interagem com o solo são o fator de retardamento (R), o coeficiente de dispersão (D) e a dispersividade $(\lambda)$. Por meio do parâmetro $R$ determina-se a relação de defasagem entre a velocidade de avanço do soluto reativo e a velocidade média da água no poro, o que indica a capacidade de retenção do solo para determinado composto, descrevendo-se as interações entre contaminantes e solo (VALOCCHI, 1984; GENUCHTEN \& WIERENGA, 1986). Os parâmetros físicos $\mathrm{D}$ e $\lambda$ levam em consideração os processos de difusão e de dispersão mecânica no solo.

Este trabalho teve como objetivo realizar um estudo de modelagem da dispersão de contaminantes em solos arenosos com AR tratadas em diferentes estações de tratamento de uma indústria siderúrgica, com fins de avaliação sobre a possibilidade, ou não, de reúso dentro do empreendimento.

\section{METODOLOGIA}

\section{Área de estudo e coleta de amostras de solo}

A indústria metalúrgica a partir da qual foi desenvolvido o estudo foi a Companhia Siderúrgica do Pecém (CSP), instalada no Complexo Industrial e Portuário do Pecém (CIPP), no município de São Gonçalo do Amarante, no estado do Ceará. A siderúrgica tem capacidade de produção de três milhões de toneladas por ano de aço bruto, sendo a placa seu principal produto.

$\mathrm{Na}$ CSP são produzidos esgoto sanitário e AR das atividades da siderúrgica oriundas do pátio de matérias-primas, da aciaria e do lingotamento contínuo, que são tratadas na CSP separadamente em quatro estações de tratamento de efluentes (ETEs): Sanitária, Principal, Pátio de Matérias-Primas (PMP) e Lingotamento Contínuo, respectivamente, totalizando, aproximadamente, $359.000 \mathrm{~m}^{3} \cdot \mathrm{mês}^{-1}$ de água residuária tratada. As AR utilizadas nos ensaios de mobilidade de contaminantes em colunas de solo saturado foram coletadas na saída das referidas ETEs de forma composta ao longo de uma hora, de maneira a se ter um volume final de $50 \mathrm{~L}$ para cada ETE. As amostras foram acondicionadas em gelo e encaminhadas para o Laboratório de Saneamento Ambiental (Labosan) do Departamento de Engenharia Hidráulica e Ambiental da Universidade Federal do Ceará, para caracterização físico-química e realização dos ensaios em coluna descritos a seguir.

As amostras de solo caracterizadas e utilizadas nos ensaios de deslocamento miscível foram coletadas no interior da CSP, em três áreas com potencial para aplicação do reúso (APAR). As áreas adotadas foram nomeadas A, B e C, nas quais podem ser utilizadas a água de reúso para irrigação de um cinturão verde no entorno da companhia, resfriamento de placas de aço e aspersão de vias não pavimentadas no interior da indústria, respectivamente. Uma vez que o reúso nessas atividades implica no lançamento das AR no solo, torna-se necessária a realização de um estudo sobre a mobilidade dos contaminantes presentes nas AR nos solos das APAR, de acordo com a Resolução Estadual COEMA $n^{\circ} 02 / 2017$, que dispõe sobre padrões e condições de reúso.

A coleta foi realizada conforme a referida legislação, sendo coletadas cinco subamostras por hectare da região em profundidades de $0-20 \mathrm{~cm}$ da superfície. Antes da coleta das subamostras foi realizada no local a remoção do horizonte $\mathrm{O}$ do solo, visando a não interferência da matéria orgânica (MO) superficial nos ensaios de mobilidade de contaminantes. Por meio do método do caminhamento dentro da APAR foram coletadas 55, 14 e 23 subamostras de mesmo volume para as áreas A (10,93 ha), B (2,64 ha) e C (4,53 ha), respectivamente. As amostras deformadas foram retiradas utilizando-se trado, seguindo estudos prévios na temática, como os de como Oliveira et al. (2010), Silva et al. (2012), Oliveira et al. (2013) e Andrade et al. (2018).

A partir da homogeneização das subamostras separadamente, foram obtidas três amostras compostas de solo, uma para cada APAR. Estas foram armazenadas em sacos plásticos limpos e utilizadas tanto para as análises de caracterização do solo quanto para os ensaios para a quantificação do transporte dos contaminantes em coluna preenchida com o solo das áreas.

Parte das amostras foi retirada por quarteamento e encaminhada ao Laboratório de Solo/Água do Departamento de Engenharia Agrícola do Centro de Ciências Agrárias da Universidade Federal do Ceará, para caracterização química e física, de acordo com as análises apresentadas nos resultados e segundo as metodologias preconizadas pelo Manual de Métodos de Análises de Solo (DONAGENA et al., 2011) para solos normais. 
O restante foi preparado para o preenchimento das colunas de solo utilizadas nos ensaios de mobilidade de contaminantes. Nessa preparação, as amostras compostas de cada região foram secas em estufa a $105^{\circ} \mathrm{C}$ por 24 horas, para estabilização da umidade, destorroadas e passadas por peneira de malha de $2,00 \mathrm{~mm}$.

\section{Determinação dos parâmetros de transporte de contaminantes}

Os ensaios de mobilidade de contaminantes em solo saturado foram realizados visando à simulação da disposição das AR das quatro ETEs nas três APAR. As amostras foram coletadas nas quatro ETEs e armazenadas em bombonas sob condição de baixa temperatura $\left(4^{\circ} \mathrm{C}\right)$.

Dessa forma, nos ensaios de mobilidade de contaminantes em colunas de solo saturado, foram combinadas as áreas de lançamento e as AR. Para que o ensaio fosse realizado em duplicata, foram construídas oito colunas de PVC com as seguintes dimensões: diâmetro interno igual a 7,5 cm, comprimento igual a $20 \mathrm{~cm}$ sendo a base das colunas vedada com gaze. A relação entre os locais onde se desejava aplicar o reúso e as ETEs potenciais é apresentada na Tabela 1.

Cada amostra de solo ensaiada na coluna tinha as seguintes condições: peso de $974,14 \mathrm{~g}$, altura de $15 \mathrm{~cm}$ e volume de $662,68 \mathrm{~cm}^{3}$, para que o solo no interior da coluna apresentasse densidade semelhante à densidade real da amostra em campo. Adicionou-se um tubo extravasor na altura de $17 \mathrm{~cm}$ da coluna, para garantir uma lâmina de água de $2 \mathrm{~cm}$ acima do solo, representando uma condição extrema de acúmulo de efluente na superfície do solo em campo.

Após isso, as colunas foram colocadas em um recipiente, para o qual foi adicionada água destilada até $2 / 3$ da altura da coluna, permitindo a expulsão do ar presente no solo por meio do fluxo ascendente da água. Esse processo durou um dia, para garantir a saturação total do solo.

Posteriormente, de modo a garantir um fluxo descendente na coluna, estas foram montadas em suportes universais e conectadas a uma bomba peristáltica da Masterflex ${ }^{\circledast}$ (modelo 77800-50) que succionava líquido de um recipiente e o recalcava para o topo de cada uma das colunas.

Inicialmente, realizou-se o ensaio de condutividade hidráulica do solo saturado, procedimento que descreve o escoamento em meios porosos. Para isso, aplicou-se água destilada até o estabelecimento de lâmina de $2 \mathrm{~cm}$ de água acima do solo. Após regime constante, foram calculados o fluxo de Darcy e a condutividade hidráulica do solo saturado, de acordo com as Equações 1 e 2.

$\mathrm{q}=\frac{Q}{A c}$

$\mathrm{K}_{0}=\frac{q}{\left(x+h_{L}\right) / x}$

Tabela 1 - Relação entre local de reúso e estações de tratamento de efluentes potenciais.

\begin{tabular}{l|c|c|c} 
Solo & Água residuária tratada & Número de colunas & Ensaio \\
A & ETE PMP & 2 & 1 \\
\hline A & ETE Sanitária & 2 & 2 \\
\hline B & ETE Lingotamento & 2 & 3 \\
\hline C & ETE Principal & 2 & 4 \\
\hline
\end{tabular}

ETE: estação de tratamento de efluente.

Fonte: elaboração própria.
Em que:

$\mathrm{q}=$ fluxo de Darcy $\left(\mathrm{cm} \cdot \mathrm{h}^{-1}\right)$;

$\mathrm{Q}=$ vazão média do líquido na coluna $\left(\mathrm{cm}^{3} \cdot \mathrm{h}^{-1}\right)$;

$\mathrm{Ac}=$ área da seção transversal da coluna $\left(\mathrm{cm}^{2}\right)$;

$\mathrm{K}_{0}=$ condutividade hidráulica do solo saturado $\left(\mathrm{cm} \cdot \mathrm{h}^{-1}\right)$;

$\mathrm{x}=$ altura de solo na coluna $(\mathrm{cm})$;

$\mathrm{h}_{\mathrm{L}}=$ altura da lâmina d'água $(\mathrm{cm})$.

A partir dos resultados, foi possível calcular a velocidade de avanço da solução percolada no solo, por meio da divisão do fluxo de Darcy pela porosidade total da amostra.

Em seguida, a aplicação de água destilada foi interrompida. Assim que a coluna deixou de apresentar a lâmina de água acima do solo, foi percolada a água residuária proveniente das ETEs (Tabela 1). Após a formação da lâmina de $2 \mathrm{~cm}$, foram coletadas em frascos plásticos 31 alíquotas de $32 \mathrm{~mL}$ para solos A e C, e $31 \mathrm{~mL}$ para solo B, totalizando 3 volumes porosos de solo em cada repetição. Cada alíquota do líquido percolado representava $10 \%$ do volume poroso do solo, sendo cronometrado o tempo para obtenção de cada uma das alíquotas.

Para as alíquotas coletadas no ensaio foram realizadas análises de $\mathrm{pH} \mathrm{e}$ condutividade elétrica, segundo metodologia descrita em APHA, AWWA e WEF (2012). Foram também quantificados os íons fluoreto, cloreto, brometo, nitrito, nitrato, fosfato, sulfato, lítio, sódio, amônio, potássio, magnésio e cálcio, utilizando-se o procedimento 4110-B do Standard Methods (APHA, AWWA \& WEF, 2012) para preparo de amostra e determinação por meio de um cromatógrafo de íons ICS-1100, da Thermo Scientific ${ }^{\mathrm{Tw}}$ Dionex $^{\mathrm{xw}}$. Também nas mesmas alíquotas foram quantificados cobre, cromo, chumbo, níquel, ferro, zinco, cálcio, magnésio e silício, utilizando-se espectrometria de emissão óptica com plasma indutivamente acoplado, com o uso do equipamento iCAP $\mathrm{P}^{\mathrm{m}} 7000$ Plus Series ICP-OES, da Thermo Scientific ${ }^{\mathrm{im}}$, com a amostra preparada de acordo com procedimento 3030-E do Standard Methods (APHA, AWWA \& WEF, 2012).

Com os valores médios entre as duas repetições foram traçadas curvas de eluição (breakthrough curves - BTC), para compreensão do comportamento das concentrações dos contaminantes a partir dos volumes porosos percolados. Para isso, utilizaram-se o número de poros e as concentrações de cada alíquota naquele instante da coleta $(C)$, relacionadas à concentração inicial da água residuária antes de passar pela coluna (Co).

Com base na equação do transporte de contaminantes no solo (Equação 3), foi possível modelar os dados que apresentaram comportamento sigmoidal e obter os parâmetros de transporte $\mathrm{R}$ e $\mathrm{D}$, utilizando-se a solução analítica para a equação de transporte (Equação 4) desenvolvida por Genuchten e Wierenga (1986). Uma curva BTC foi desenvolvida para cada elemento passível de modelagem (comportamento sigmoidal), utilizando-se a média de concentração das duas repetições.

$\frac{\partial C}{\partial t}=D_{L} \frac{\partial^{2} C}{\partial x^{2}}-v_{x} \frac{\partial C}{\partial x}-\frac{B_{d}}{\theta} \frac{\partial C^{*}}{\partial t}+\left(\frac{\partial C}{\partial t}\right)_{r x n}$

Em que:

$\mathrm{C}=$ concentração do soluto na fase líquida;

$\mathrm{t}=$ tempo;

$\mathrm{D}_{\mathrm{L}}=$ coeficiente de dispersão longitudinal;

$\mathrm{v}_{\mathrm{x}}=$ velocidade média da água subterrânea;

$\mathrm{B}_{\mathrm{d}}=$ densidade volumétrica do aquífero; 
$\theta=$ quantidade de umidade ou porosidade do meio saturado;

$\mathrm{C}^{*}=$ quantidade de soluto sorvido por unidade de massa sólida;

rxn = subscrito que indica reação química ou biológica (outra que não sorção).

$\frac{C}{C_{o}}=\frac{1}{2}\left[\operatorname{erfc}\left(\frac{R x-v t}{\sqrt{4 D R t}}\right)-\left(1+\frac{v x}{D}+\frac{v^{2} t}{D R}\right) e^{(v x / D)} \operatorname{erfc}\left(\frac{R x+v t}{\sqrt{4 D R t}}\right)|+| \frac{v^{2} t}{\pi D R} e^{\left|-\frac{(R x-v t)^{2}}{4 D R t}\right|}\right.$

Em que:

$\mathrm{C}=$ concentração do soluto na solução efluente $\left(\mathrm{mg} \cdot \mathrm{L}^{-1}\right)$;

$\mathrm{Co}=$ concentração da solução deslocadora $\left(\mathrm{mg} \cdot \mathrm{L}^{-1}\right)$;

$\mathrm{R}=$ fator de retardamento;

$\mathrm{t}=$ tempo $(\mathrm{h})$;

$\mathrm{D}=$ coeficiente de dispersão hidrodinâmica $\left(\mathrm{cm}^{2} \cdot \mathrm{h}^{-1}\right)$;

erfc $=$ função erro complementar;

$\mathrm{v}=$ velocidade de avanço na coluna de solo $\left(\mathrm{cm} \cdot \mathrm{h}^{-1}\right)$.

Por meio da Equação 5 obteve-se a dispersividade do meio poroso $(\lambda)$, parâmetro relacionado a características do próprio solo.

$\lambda=\frac{D}{v^{n}}$

Em que:

$\lambda=$ dispersividade no meio poroso $(\mathrm{cm})$;

$\mathrm{D}=$ coeficiente de dispersão hidrodinâmica $\left(\mathrm{cm}^{2} \cdot \mathrm{h}^{-1}\right)$;

$\mathrm{v}=$ velocidade de avanço na coluna de solo $\left(\mathrm{cm} \cdot \mathrm{h}^{-1}\right)$;

$\mathrm{n}=$ constante empírica, aproximadamente igual a 1.

Os elementos que não foram detectados pelos equipamentos utilizados não permitiram análises subsequentes. Já os elementos presentes nas AR, mas que apresentaram elevadas variações da concentração de saída ao longo do tempo, indicando comportamento de eluição temporal, e não de adsorção, não permitiram o uso de modelagem, sendo sua análise feita a partir da sua variação de saída.

\section{RESULTADOS E DISCUSSÃO}

\section{Caracterização do solo}

Os solos das três áreas de disposição foram classificados como Neossolo Quartzarênico. Os resultados obtidos nas análises estão apresentados nas Tabelas 2 e 3.

Os solos das três regiões apresentaram características físicas semelhantes, com classificação textural de areia e baixa presença de argila, cuja composição variou entre 75 e $102 \mathrm{~g} \cdot \mathrm{kg}^{-1}$. Segundo Basso e Kiang (2017), esses valores indicam baixa capacidade de retenção de contaminantes no solo, uma vez que as argilas apresentam cargas elétricas na sua superfície que influenciam a retenção dos íons. Ademais, solos arenosos apresentam predominância de macroporos, $\mathrm{o}$ que favorece a infiltração da água (BASSO \& KIANG, 2017; ANDRADE et al., 2018). A porosidade total calculada para os solos A e $C$ foi de $46,9 \%$, enquanto a do solo B foi de $46,8 \%$.

Os solos A, B e C apresentam baixas concentrações de íons do complexo sortivo e, consequentemente, baixos valores de capacidade de troca catiônica $(\mathrm{T})$ $\left(<5 \mathrm{cmol}_{\mathrm{c}} \cdot \mathrm{kg}^{-1}\right)$, segundo a classificação de Sobral et al. (2015). Isso implica que o solo tem baixa capacidade de retenção de cátions lançados, assim como menor resistência a variações de $\mathrm{pH}$. Os valores de $\mathrm{Al}^{3+}$ iguais a zero indicam que o solo não apresenta acidez trocável e saturação por alumínio (m) também igual a zero.

$\mathrm{O}$ pH em água dos três solos não indica interferência na solubilidade dos elementos, uma vez que se encontram na faixa de neutralidade. Os resultados de $\mathrm{pH}$ em $\mathrm{KCl}$ e $\mathrm{pH}$ em água indicam que há predominância de cargas negativas no solo (ALBUQUERQUE et al., 2000). Segundo Castro et al. (2010), o $\mathrm{pH}$ neutro favorece a redução da $\mathrm{T}$.

Tabela 2 - Composição granulométrica, densidade, complexo sortivo dos solos A, B e C.

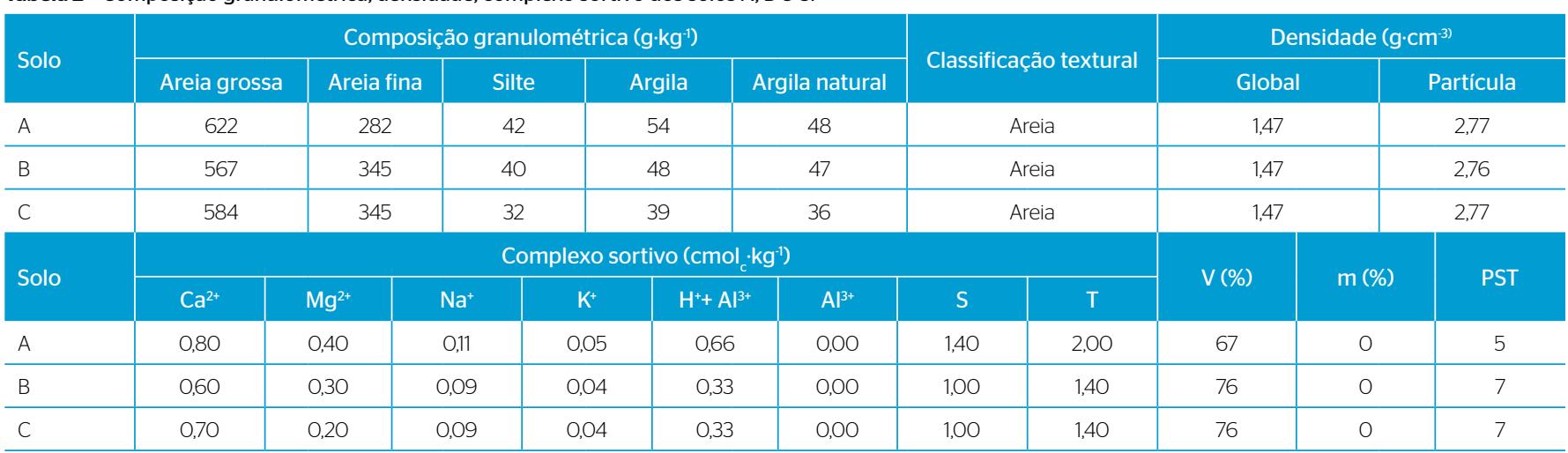

S: soma de bases; T: capacidade de troca catiônica; V: saturação por base; m: saturação por alumínio; PST: percentual de sódio trocável. Fonte: elaboração própria.

Tabela 3 - Análises de pH, pH em KCl, condutividades elétricas, matéria orgânica, instante da coleta, nitrogênio e razão de adsorção de sódio.

\begin{tabular}{|c|c|c|c|c|c|c|c|}
\hline Solo & pH em água & $\mathrm{pH}$ em KCl & $\mathrm{CE} d \mathrm{dS} \cdot \mathrm{m}^{-1}$ & $\mathrm{MO} \mathrm{g} \cdot \mathrm{kg}^{-1}$ & $\begin{array}{c}\mathrm{C} \\
\mathrm{g} \cdot \mathrm{kg}^{-1}\end{array}$ & $\underset{\mathrm{g} \cdot \mathrm{kg}^{-1}}{\mathrm{~N}}$ & RAS \\
\hline A & 7,1 & 6,1 & 0,15 & 0,52 & 0,30 & 0,03 & 2,30 \\
\hline B & 6,8 & 6,2 & 0,12 & 0,31 & 0,18 & 0,02 & 2,14 \\
\hline C & 7,5 & 6,9 & 0,12 & 1,03 & 0,60 & 0,06 & 2,17 \\
\hline
\end{tabular}

CE: condutividade elétrica; MO: matéria orgânica; C: carbono; N: nitrogênio; RAS: razão de adsorção de sódio.

Fonte: elaboração própria. 
O solo não apresentou problemas quanto à salinidade e/ou à sodicidade, uma vez que não foi caracterizado como salino (CE $>4 \mathrm{dS} \cdot \mathrm{m}^{-1}$ e PST $\left.<15 \%\right)$, sódico (CE $<4 \mathrm{dS} \cdot \mathrm{m}^{-1}$ e PST $\left.>15 \%\right)$ ou salino-sódico (CE $>4 \mathrm{dS} \cdot \mathrm{m}^{-1}$ e PST $>$ $15 \%)$, de acordo com a classificação adotada por Santos et al. (2018). No entanto, as condutividades elétricas (CE) entre 0,12 e 0,15 dS. $\mathrm{m}^{-1}$ indicam que os solos estão intemperizados (MATOS, 2010). Portanto, o lançamento contínuo de AR ricas em sódio pode acarretar aumento da salinidade e sodicidade do solo, sendo observado por Abd-Elwahed (2019) um aumento de 103\% da CE com aplicação de esgoto doméstico.

Segundo Sobral et al. (2015), o teor de MO dos solos é considerado baixo $\left(<15 \mathrm{~g} \cdot \mathrm{kg}^{-1}\right)$, o que influencia a baixa T. Ademais, a quantidade reduzida de MO também diminuiu o potencial de retenção de contaminantes do solo (NYSTRAND et al., 2016; KWIATKOWSKA-MALINA, 2018). As quantidades baixas de $\mathrm{MO}$ e $\mathrm{C}$ podem ter sido acentuadas pela remoção do horizonte O do solo durante a coleta.

\section{Parâmetros de transporte para sódio, potássio, cálcio, cloreto, nitrito e sulfato}

Dentre todos os íons e metais analisados nas AR produzidas na indústria siderúrgica, as concentrações de fluoreto, brometo, nitrato, fosfato, lítio, amônio, magnésio, cobre, cromo, chumbo, níquel e silício, ficaram abaixo do limite de detecção dos equipamentos utilizados, por isso não foram quantificados. Os demais (cloreto, nitrito, sulfato, sódio, potássio, cálcio, ferro e zinco) foram detectados nas AR e puderam ter comportamento no solo avaliado. No entanto, zinco e ferro serão analisados a seguir, uma vez que não apresentaram comportamento sigmoidal, não sendo possível obter os parâmetros de transporte desses elementos.

Os ensaios com água destilada indicaram valores de condutividade hidráulica em meio saturado (K) de 66,86, 17,46 e 100,96 cm. $\mathrm{h}^{-1}$ para os solos A, B e $C$, respectivamente, bem como velocidades médias de avanço na coluna (v) de 161,$45 ; 42,26$ e $243,81 \mathrm{~cm} \cdot \mathrm{h}^{-1}$. Andrade et al. (2018) estabelecem valores de $\mathrm{K}$ de $14,73 \mathrm{~cm} \cdot \mathrm{h}^{-1} \mathrm{em}$ solo arenoso com $796 \mathrm{~g} \cdot \mathrm{kg}^{-1} \mathrm{de}$ areia. Relacionando-se os resultados de $\mathrm{K}$ encontrados neste trabalho com os valores de areia apresentados na Tabela 2, pode-se afirmar que os valores de K dos solos da CSP são considerados elevados. Tal comportamento é decorrente da estruturação granular (areia grossa) do solo utilizado no estudo, que apresenta maior quantidade de macroporos, favorecendo o fluxo de água.

Oliveira et al. (2010), Matos et al. (2013) e Basso e Kiang (2017) indicaram que valores elevados de $\mathrm{K}$ e v influenciaram a adsorção dos contaminantes lançados no solo, já que representam menor tempo de contato entre os solutos e os sítios de troca de carga das partículas.

É possível que o lançamento constante das AR gere alteração de características físicas, químicas e biológicas do solo, acarretando mudança do comportamento deste em relação à retenção de contaminantes. Esse fenômeno foi verificado por Ababsa et al. (2020) em estudo que encontrou que o lançamento de efluentes urbanos resultou no aumento da porosidade e do transporte de água via condutividade hidráulica de um solo argiloso (13\% de areia). Os autores também indicam contribuições do lançamento da água residuária para a porosidade microbiológica do solo, afetando o transporte de contaminantes, especialmente na superfície.

Os solos das áreas A, B e C demonstraram baixa capacidade de reter os compostos, sendo o potássio o único com fator de retardamento acima de 1 (Tabela 4). No geral, os valores de R abaixo de 1 indicam interação muito baixa dos solutos com a fração coloidal do solo, o que se dá, principalmente, pelo baixo teor de argila e pelo fraco poder competidor dos elementos pelos sítios de troca do solo, aliados a altas velocidades de infiltração do líquido percolador. Os coeficientes de dispersão (Tabela 4) obtidos indicam a tendência ao rápido aumento da pluma de contaminação dos materiais, pelo comportamento dispersivo dos contaminantes.

O transporte dispersivo apresenta relação direta com a velocidade de avanço da solução no perfil do solo. As curvas BTC obtidas para os elementos estão representadas nas Figuras 1 a 6.

A curva obtida para o parâmetro sódio forneceu valor de $\mathrm{r}^{2}$ acima de 0,90 para todos os ensaios, indicando correlação adequada entre os valores experimentais e os ajustados. A concentração relativa de 0,5 é obtida antes da percolação de 1 volume poroso, estando a curva deslocada para esquerda, o que indica que não há reação do soluto com as partículas do solo, tal como verificado por Nielsen e Biggar (1962) na análise de curvas de eluição. Essa tendência é reforçada pelos valores de $\mathrm{R}$ abaixo de 1 e pelos valores de $\mathrm{D}$ altos. Nos ensaios $2 \mathrm{e}$ 4 é possível observar altas concentrações de saída, já para 0,1 volume poroso percolado da solução, sendo essas de 54,8 e 35,93\%, respectivamente. Os parâmetros de transporte obtidos apresentaram grande variação entre os ensaios, 0 que se justifica pelas diferenças na composição do solo e das AR.

Silva et al. (2012) estudaram o comportamento dos íons sódio e potássio presentes na vinhaça em colunas de solo com predominância de argila e observaram menor reatividade do sódio com o solo, em comparação com o potássio. No presente trabalho, observou-se fenômeno semelhante, inclusive com maior valor de D para o sódio. Santos et al. (2010) apresentaram valores de R de 1,485 e 2,335 para o sódio e valores de D de 216,036 e 144,904 em solos com 637 e $926 \mathrm{~g} \cdot \mathrm{kg}^{-1}$ de areia, respectivamente, em estudo utilizando efluente doméstico tratado. Ou seja, já que as partículas dos solos não reagem com o sódio presente no efluente, há baixo risco de salinização.

Tabela 4 - Valores médios obtidos de fator de retardamento, coeficiente de dispersão hidrodinâmica, dispersividade do meio poroso e coeficiente de determinação.

\begin{tabular}{|c|c|c|c|c|c|}
\hline Elemento & Ensaio & $\mathbf{R}$ & $\mathrm{D}\left(\mathrm{m}^{2} \cdot \mathrm{dia}^{-1}\right)$ & $\lambda(\mathrm{m})$ & $r^{2}$ \\
\hline \multirow{4}{*}{ Sódio } & 1 & 0,65 & 2,05 & 0,05 & 0,96 \\
\hline & 2 & 0,01 & 1366,19 & 35,26 & 0,91 \\
\hline & 3 & 0,31 & 0,67 & 0,07 & 0,99 \\
\hline & 4 & 0,13 & 42,03 & 0,72 & 0,94 \\
\hline \multirow{2}{*}{ Potássio } & 1 & 1,67 & 1,23 & 0,03 & 0,95 \\
\hline & 2 & 1,28 & 14,96 & 0,37 & 0,84 \\
\hline Cálcio & 1 & 0,56 & 10,33 & 0,27 & 0,85 \\
\hline \multirow{4}{*}{ Cloreto } & 1 & 0,06 & 88,33 & 2,28 & 0,86 \\
\hline & 2 & 0,01 & 2160,00 & 55,74 & 0,66 \\
\hline & 3 & 0,24 & 0,53 & 0,05 & 0,97 \\
\hline & 4 & 0,09 & 28,80 & 0,49 & 0,87 \\
\hline Nitrito & 1 & 0,12 & 11,51 & 0,30 & 0,79 \\
\hline \multirow{4}{*}{ Sulfato } & 1 & 0,62 & 1,49 & 0,04 & 0,95 \\
\hline & 2 & 0,26 & 5,70 & 0,15 & 0,84 \\
\hline & 3 & 0,08 & 3,23 & 0,32 & 0,84 \\
\hline & 4 & 0,09 & 21,81 & 0,37 & 0,77 \\
\hline
\end{tabular}

R: fator de retardamento; D: coeficiente de dispersão hidrodinâmica; $\lambda$ : dispersividade do meio poroso; $r^{2}$ : coeficiente de determinação. Fonte: elaboração própria. 
$\mathrm{O} \mathrm{K}^{+}$foi passível de modelagem apenas para os ensaios de mobilidade utilizando o solo A. De acordo com o discutido por Nielsen e Biggar (1962) e Matos et al. (2013), para análise da curva de eluição de acordo com a relação C/Co de 0,5 , quanto mais acima da unidade é o número de volumes porosos, maior é a interação entre solo e soluto. Assim, verifica-se uma tendência a retardamento maior do potássio, quando em comparação com os outros elementos, estando sua curva deslocada para a direita e sendo a concentração relativa de 0,5 obtida apenas para 1,5 e 1,7 volumes porosos para os ensaios 1 e 2, respectivamente. Isso indica preferência do solo pela retenção de $\mathrm{K}^{+}$em relação aos outros íons, tendência confirmada pelos valores de R acima da unidade e pelos baixos valores para $\mathrm{D}$, se comparado aos demais. Apesar de ser um cátion monovalente, o que conferiria menor força de atração do íon pela fração coloidal do solo, a elevada concentração do potássio na solução percoladora pode justificar o fato de o elemento ser mais retido pelo solo.
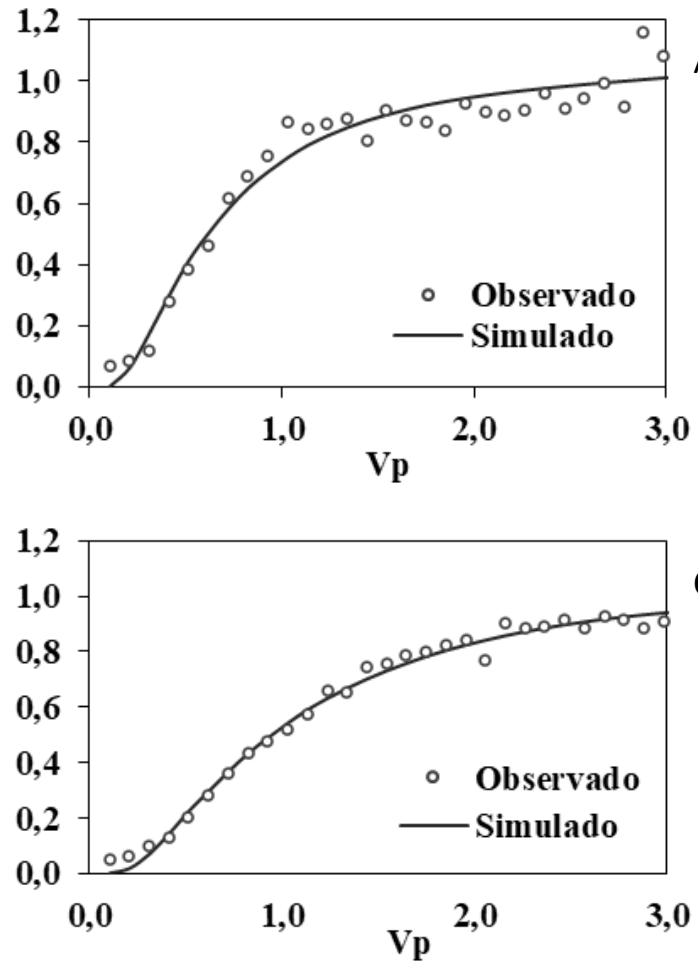

A
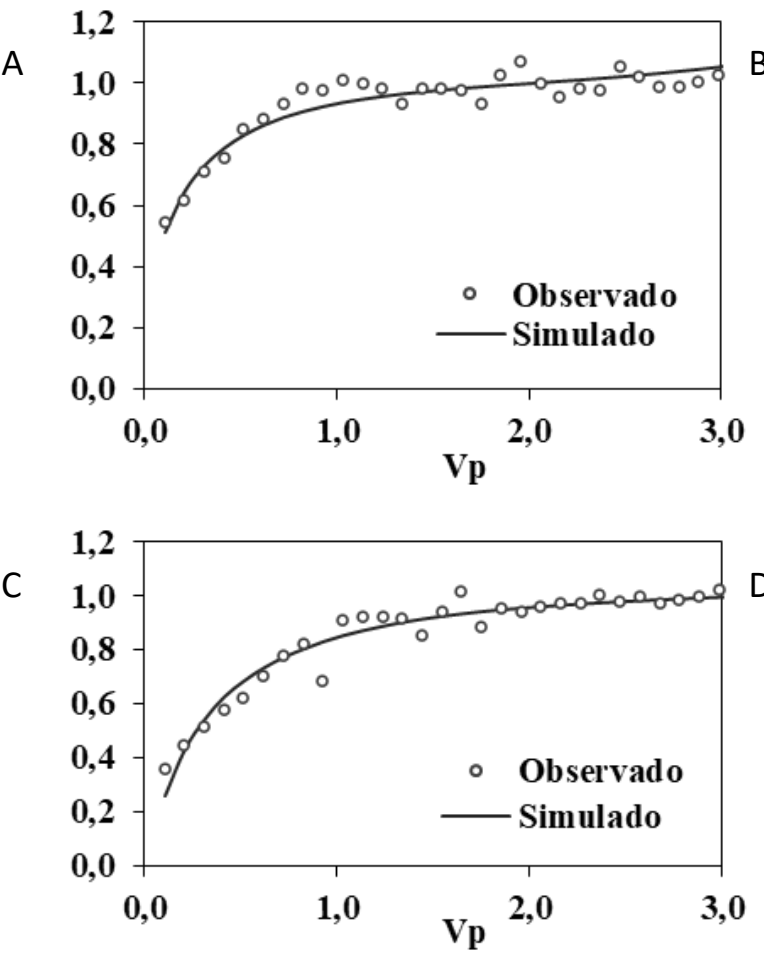

VP: volumes porosos

Fonte: elaboração própria.

Figura 1 - Curvas de eluição do sódio nos ensaios 1 (A), 2 (B), 3 (C) e 4 (D)
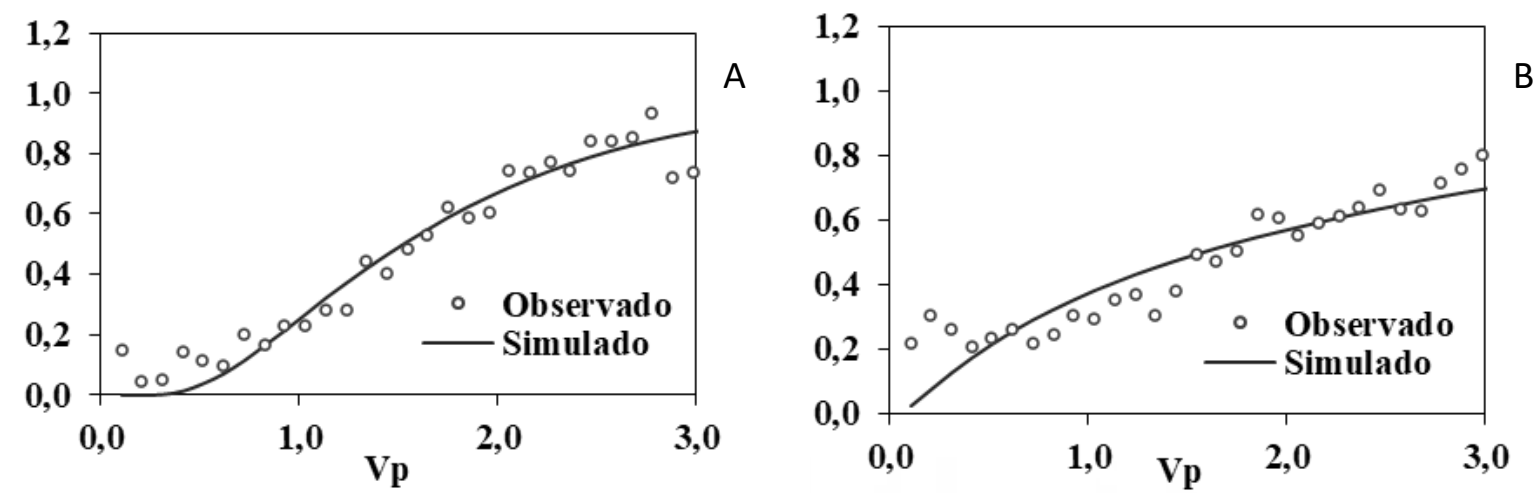

VP: volumes porosos.

Fonte: elaboração própria.

Figura 2 - Curvas de eluição do potássio nos ensaios 1 (A), 2 (B). 
Matos et al. (2013) encontraram comportamento semelhante em experimento com a aplicação de água residuária proveniente da vinhaça em um latossolo. No referido estudo, foram obtidos: R de 2,17, D de $3,44 \mathrm{~cm}^{2} \cdot \mathrm{h}^{-1}$, classificação textural franco-argilo-arenosa com T de $6,54 \mathrm{cmolc} \cdot \mathrm{kg}^{-1}$ (o triplo dos valores encontrados na presente investigação) e matéria orgânica de 40,13 $\mathrm{g} \cdot \mathrm{kg}^{-1}$. Tais condições indicam capacidades de retenção muito maiores, quando comparadas às verificadas no presente estudo. Em experimento utilizando solução percoladora sintética com concentrações elevadas de $\mathrm{K}^{+}$, variando de 250 a $1.000 \mathrm{mg} \cdot \mathrm{L}^{-1}$, Basso e Kiang (2017) obtiveram valores de R entre 9 e 5,3 em solo arenoso com T de 2,0 cmolc. $\mathrm{kg}^{-1}$. Para ensaio de coluna utilizando solo

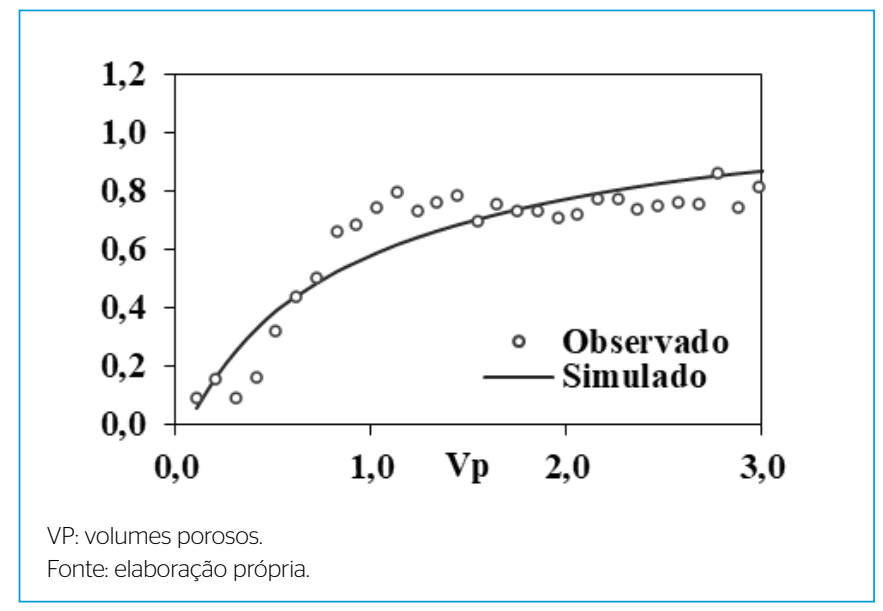

Figura 3 - Curva de eluição do cálcio no ensaio 1. com $796 \mathrm{~g} \cdot \mathrm{kg}^{-1}$ de teor de areia e uso de água residuária sanitária, Andrade et al. (2018) encontram R de 1,12 e D de $13,61 \mathrm{~cm}^{2} \cdot \mathrm{min}^{-1}$.

Apesar de o $\mathrm{r}^{2}$ da curva de eluição do cálcio ser considerado satisfatório $(>0,85)$, o ajuste visual não é preciso (Figura 3), o que pode se dar pela concentração relativa de, aproximadamente, 0,1 já para o primeiro volume poroso. Para C/ Co de 0,5 , o número de volumes porosos coletados é inferior a 1, com a curva deslocada para a esquerda, indicando baixa reação do soluto com o solo e caracterizando predominância do transporte dispersivo (NIELSEN \& BIGGAR, 1962).

Esse mesmo comportamento de curva foi obtido para o cálcio no trabalho de Santos et al. (2010), em um neossolo regolítico com predominância de

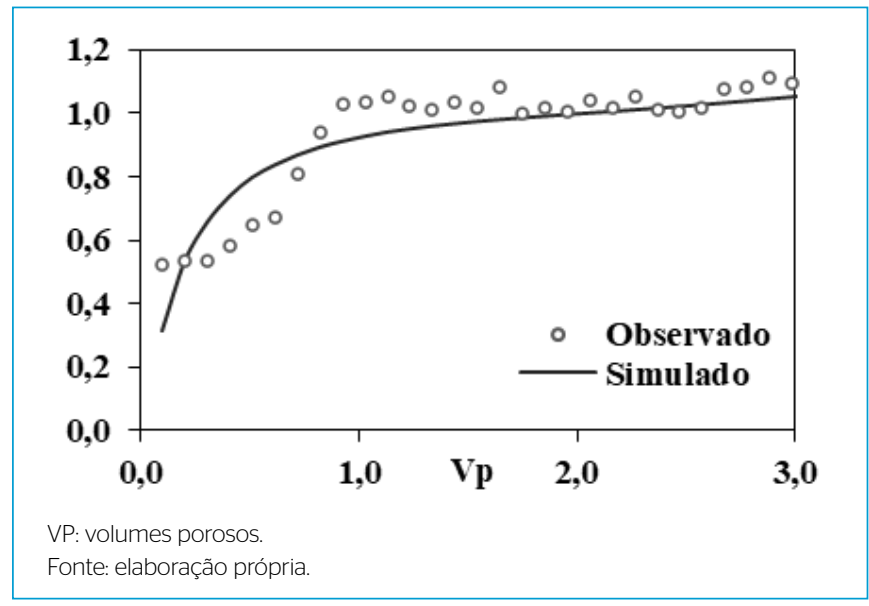

Figura 5 - Curva de eluição do nitrito no ensaio 1.
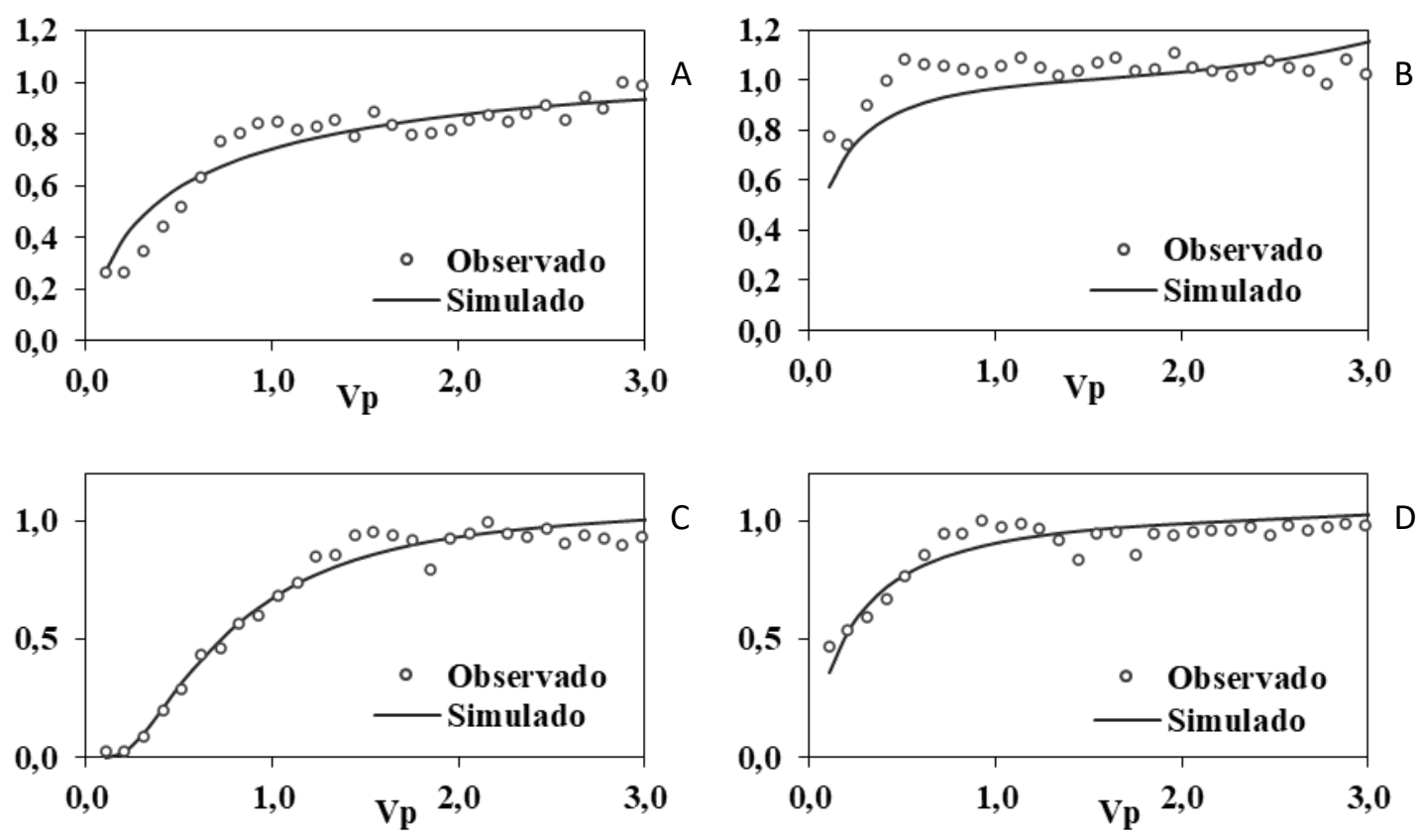

VP: volumes porosos.

Fonte: elaboração própria.

Figura 4 - Curvas de eluição do cloreto nos ensaios 1 (A), 2 (B), 3 (C) e 4 (D). 
areia. No referido estudo, os valores de R obtidos para o cálcio foram de 1,669 e 1,514, respectivamente, com uso de água residuária doméstica e de suinocultura. Os valores de R muito mais altos obtidos por Santos et al. (2010) podem ser justificados pelo fato de a concentração de $\mathrm{MO}$ no solo utilizado ser cerca de 13 vezes maior do que a do solo A, reduzindo consideravelmente a sorção de compostos. Em solo com $67 \mathrm{dag} \cdot \mathrm{kg}^{-1}$ de areia, T de 6,54 cmolc. $\mathrm{dm}^{-3} \mathrm{e} \mathrm{MO}$ de 4,13 dag. $\mathrm{kg}^{-1}$, Matos et al. (2013) encontraram R de 1,27 e D de 9,01 $\mathrm{cm}^{2} \cdot \mathrm{h}^{-1}$.

As curvas de eluição do cloreto são apresentadas na Figura 4 . O cloreto obteve valores de R que variam entre 0,01 e 0,24, o que indica a quase não existência de sorção do elemento pelas partículas do solo. Os valores de D apontam para predominância dos transportes advectivo e dispersivo para esse elemento. Para os ensaios 1,2 e 4 com o escoamento de 0,1 volumes porosos já há liberação de, respectivamente, $26,65,57,26$ e 35,81\% do cloreto presente nas AR. O elemento não teve o mesmo comportamento no ensaio 3 , o que justifica o $R$ mais elevado. O escoamento pode ter sido acentuado pela predominância de cargas eletronegativas dos solos. Em ensaio de coluna com solo arenoso, Basso e Kiang (2017) também observaram alta mobilidade do cloreto e baixa sorção na coluna. No entanto, ainda assim foram obtidos valores de R entre 2,39 e 2,94 e de D entre 0,021 e $0,042 \mathrm{~cm}^{2} \cdot \mathrm{min}^{-1}$ o que pode ser justificado pela percolação de solução artificial.

$\mathrm{O}$ ajuste visual da curva do nitrito (Figura 5) não indica que o modelo tenha atendido à movimentação do elemento. De acordo com a curva observada, infere-se que há, principalmente, os transportes adsorsivos e dispersivos para esse contaminante, sendo o composto quase completamente lixiviado pelo solo. As concentrações relativas acima de 1 indicam que houve dessorção do elemento já presente no solo (CONCIANI, 2016).

As curvas de eluição do sulfato são apresentadas na Figura 6. O sulfato também apresentou valores de $\mathrm{R}$ abaixo da unidade. Os ensaios com solo $\mathrm{A}$ demonstraram haver maior capacidade de retenção em comparação aos outros solos, mas, ainda assim, os valores indicam tendência à lixiviação do elemento ao longo do perfil do solo, o que também foi apontado por Luchese et al. (2008). O valor de R obtido para o sulfato no ensaio 1 foi maior ou próximo aos valores de R para cátions, o que não é previsto para solos com predominância de cargas eletronegativas. Possivelmente, a elevada concentração (cerca de $265 \mathrm{mg} \cdot \mathrm{L}^{-1}$ ) deste nas AR pode ter deslocado outros íons, fazendo com que houvesse preferência por ele nas trocas iônicas ocorrentes no solo.

\section{Metais com comportamento de eluição temporal}

Os metais detectados nos ensaios (zinco e ferro) apresentaram concentrações de saída das colunas com comportamento bastante errático, não sendo passíveis de modelagem de acordo com a equação de transporte de contaminantes. As curvas médias de eluição obtidas para zinco e ferro estão representadas nas Figuras 7 e 8, respectivamente.

Em todos os ensaios, o zinco mostrou comportamento irregular quanto à sua retenção pelo solo, passando por grandes variações. A inconstância no comportamento de retenção do zinco pode ser explicada pela sua baixa concentração nas $\mathrm{AR}\left(0,16,0,23,0,30\right.$ e $\left.0,01 \mathrm{mg} \cdot \mathrm{L}^{-1}\right)$, o que faz com que os outros
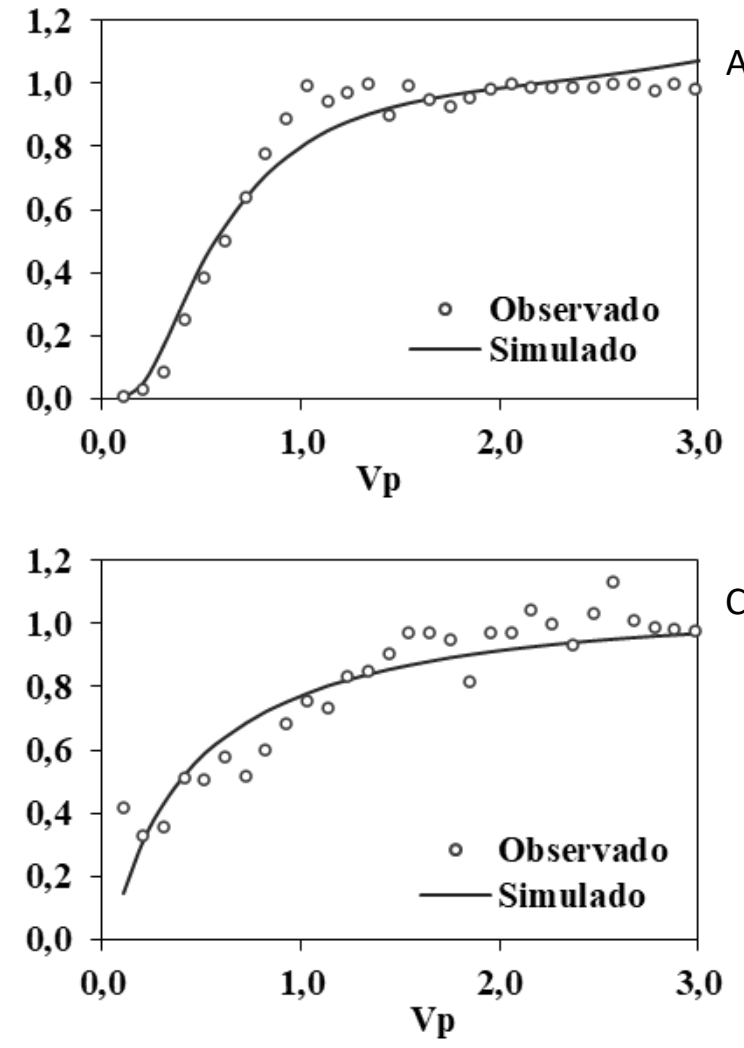
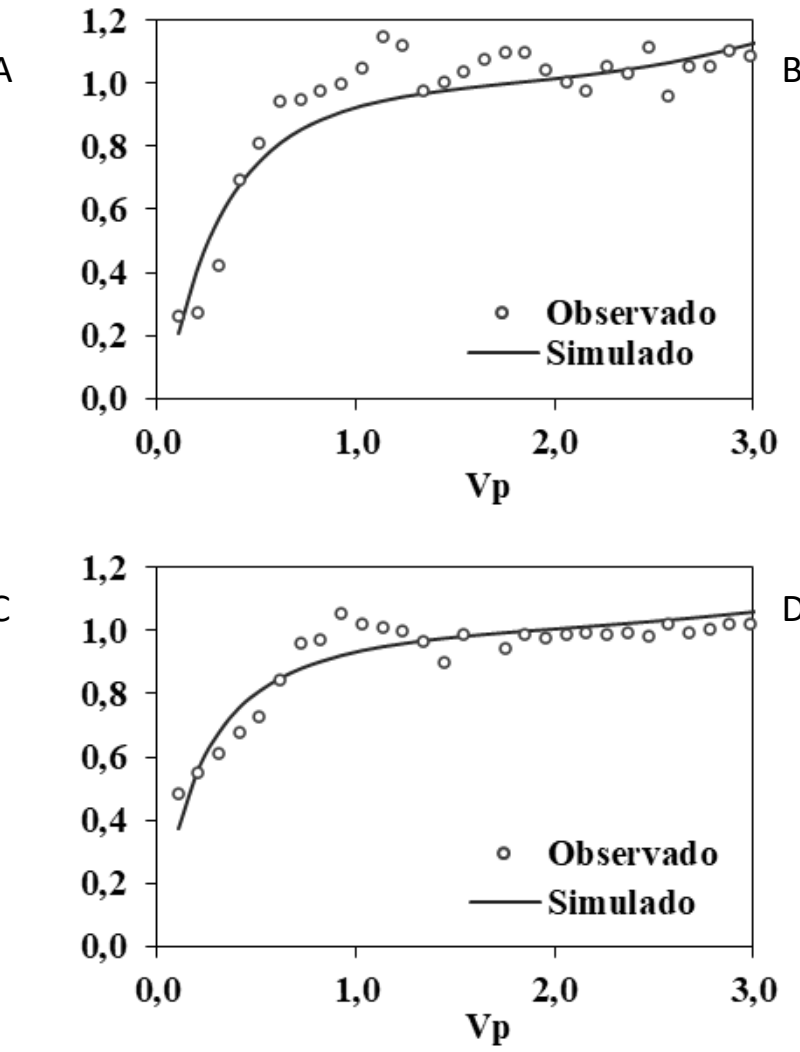

VP: volumes porosos.

Fonte: elaboração própria.

Figura 6 - Curvas de eluição do sulfato nos ensaios 1 (A), 2 (B), 3 (C) e 4 (D). 
elementos presentes em maior concentração tenham preferência no processo de retenção no solo. Assim, ressalta-se a tendência de lixiviação do zinco por meio do solo nessas condições. Em outros estudos, o zinco aparece com valores de retardamento na faixa de 6 para solo arenoso-argiloso (FONSECA et al., 2011), o que revela sua tendência à retenção no solo, para outras condições de concentração no líquido percolador e da composição do solo. Moreira et al. (2010) reportam tendência à redução do retardamento do metal conforme se aumenta a fração granulométrica do solo. Na avaliação de mobilidade de contaminantes presentes em resíduos siderúrgicos (lama de carepa de aciaria, lama de fosfato e lama de filtro-prensa), verificou-se tendência de elevada mobilidade do zinco presente nos resíduos. Tal fato foi atribuído à própria presença desse elemento no solo, predominantemente em formas trocáveis, portanto, facilmente solúveis, indicando preocupação quanto à contaminação das águas subterrâneas por esse metal (NASCIMENTO et al., 2010).

O ensaio 1 registrou ferro apenas no primeiro volume poroso escoado, indicando que, no momento em que se percola um volume poroso do líquido, há dessorção do ferro retido no solo, provocada para liberação de sítios de carga das partículas do solo e consequente retenção de outros compostos. No ensaio 2 ,

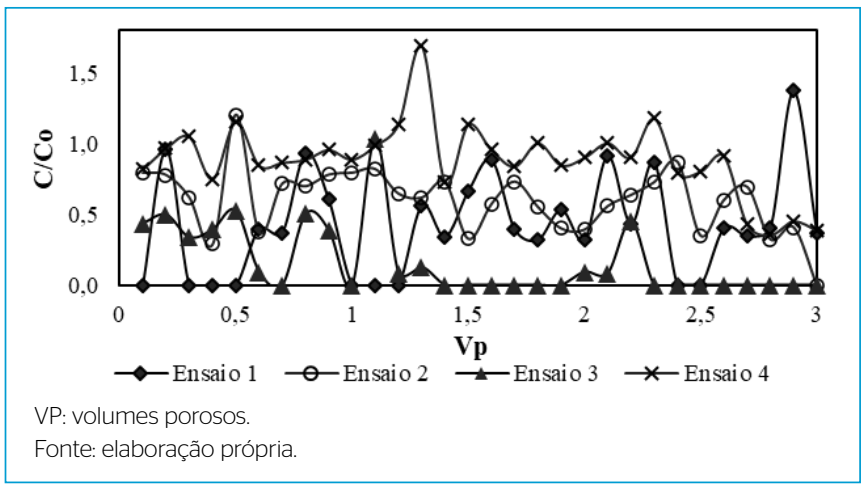

Figura 7 - Curva de eluição média para o zinco nos ensaios 1, 2, 3 e 4.

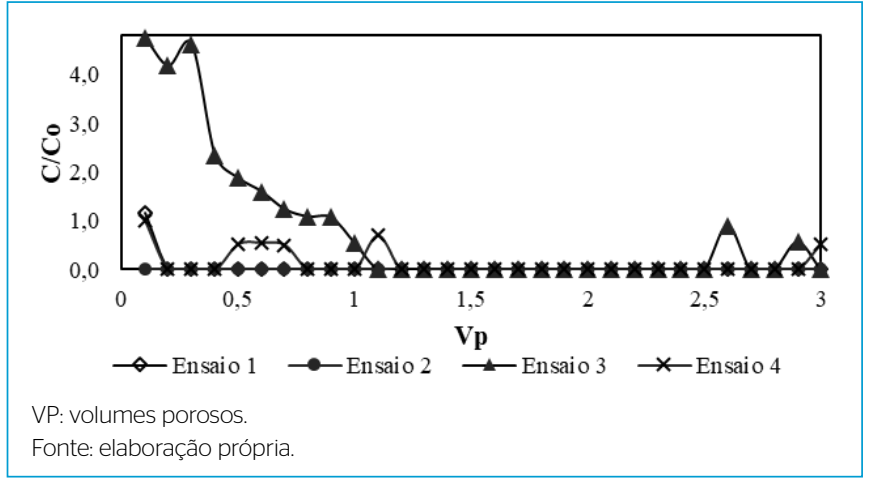

Figura 8 - Curva de eluição média para o ferro nos ensaios 1, 2, 3 e 4. com efluente sanitário, não foi detectada a presença de ferro. Para obtenção das curvas dos ensaios 3 , foi necessário estabelecer uma concentração inicial de ferro de $0,1 \mathrm{mg} \cdot \mathrm{L}^{-1}$, limite de detecção do equipamento utilizado na análise de metais. A partir disso, pode-se verificar a dessorção do elemento nos dois ensaios com o solo B. Para o ensaio 4 também foram observados episódios de retenção do elemento, ocasionado pela liberação momentânea de sítios de carga das partículas do solo. No geral, os solos demonstraram tendência à lixiviação do ferro.

Uma vez que os solos das APAR apresentam baixa capacidade de retenção dos contaminantes presentes nos efluentes estudados, o risco de contaminação da água subterrânea se torna uma preocupação mais relevante do que a saturação do solo por esses elementos. Dessa forma, o reúso de AR em áreas com neossolos quartizarênicos deve ser cuidadosamente pensado, englobando medidas de manejo, como, por exemplo: técnicas de recomposição do horizonte $\mathrm{O}$ com inserção de matéria orgânica e manutenção de cobertura vegetal; formação de barreiras com solos argilosos; usos de sistemas de irrigação localizada para dispor a água residuária, visto que reduzem o risco de escoamento superficial e controlam a perda de água por percolação profunda, diminuindo a mobilidade dos contaminantes. Para os pátios da indústria siderúrgica, como em áreas de resfriamento de placas, a impermeabilização pelo uso de geossintéticos, entre outras, pode ser avaliada como alternativa para a retenção do percolado, funcionando como barreira física e evitando/minimizando a eventual contaminação das águas subterrâneas.

\section{CONCLUSÕES}

Os solos coletados demonstraram baixa capacidade de retenção dos elementos estudados, indicando que haveria riscos de contaminação da água subterrânea devido à tendência de lixiviação dos contaminantes no solo (coeficientes de retardamento abaixo de 1 ).

Com base nos resultados obtidos neste trabalho, as aplicações de AR em solos arenosos com quantidade de argila de até $54 \mathrm{~g} \cdot \mathrm{kg}^{-1} \mathrm{e}$ quantidade de matéria orgânica de até $1,03 \mathrm{~g} \cdot \mathrm{kg}^{-1}$ apresentam risco ambiental em termos de contaminação de água subterrânea.

Não obstante, podem ser adotadas técnicas de manejo de solo ou de impermeabilização na área de resfriamento de placas que permitam o reúso não potável seguro em atividades siderúrgicas.

\section{CONTRIBUIÇÃO DOS AUTORES}

Carvalho, C.B.: Conceituação, Curadoria de Dados, Análise Formal, Metodologia, Escrita - Primeira Redação. Pereira, E. L.: Conceituação, Metodologia, Escrita Revisão e Edição. Santos, A. B.: Conceituação, Obtenção de Financiamento, Supervisão, Escrita - Revisão e Edição.

\section{REFERÊNCIAS}

ABABSA, N.; KRIBAA, M.; TAMRABET, L.; ADDAD, D.; HALLAIRE, V:; OULDJAOUI, A. Long-term effects of wastewater reuse on hydro physicals characteristics of grassland grown soil in semi-arid Algeria. Journal of King Saud University Science, v. 33, n. 1, p. 1004-1013, 2020. https://doi.org/10.1016/j.jksus.2019.09.007
ABD-ELWAHED, M. S. Effect of long-term wastewater irrigation on the quality of alluvial soil for agricultural sustainability. Annals of Agricultural Sciences, v. 64, n. 2, p. 151-160, 2019. https://doi.org/10.1016/j. aoas.2019.10.003 
ALBUQUERQUE, J. A.; BAYER, C.; ERNANI, P. R.; FONTANA, E. C. Propriedades físicas e eletroquímicas de um Latossolo Bruno afetadas pela calagem. Revista Brasileira de Ciência do Solo, v. 24, n. 2, p. 295-300, 2000. https://doi. org/10.1590/S0100-06832000000200006

ANDRADE, C. W. L; MONTENEGRO, S. M. G. L;:MIRANDA, J. H: MONTENEGRO, A. A. A: ASSIS, F. M. C. V. Simulation of sodium and potassium dynamics by the HYDRUS 2D model in a haplic planosol via residue water. Engenharia Agrícola, v. 38, n.36, p.874-884, 2018. https://doi.org/10.1590/1809-4430-Eng.Agric.v38n6p874-884/2018

AMERICAN PUBLIC HEALTH ASSOCIATION (APHA); AMERICAN WATER WORKS ASSOCIATION (AWWA); WATER ENVIRONMENT FEDERATION (WEF). Standard Methods for the Examination of Water and Wastewater. $22^{\mathrm{a}}$ ed. Washington, D.C.: APHA/AWWA/WEF, 2012.

BASSO, J. B: KIANG, C. H. Retardamento e dispersão hidrodinâmica de cobre, potássio e cloreto em solos residuais do subgrupo itararé no estado de São Paulo. Águas Subterrâneas, v. 31, n. 1, p. 117-133, 2017. https://doi.org/10.14295/ras.v31i1.28638

CASTRO, M. L. L.; BORGES, J. D.; OLIVEIRA, L. F. C.; RODRIGUES, C.; FIGUEIREDO, C. C.; CASTRO, W. J. Sorção de cromo em solos do cerrado goiano, Brasil. AmbiÁgua, v. 5, n. 2. p. 133-143, 2010. https://doi.org/10.4136/ambi-agua.143

COLLA, V.; MATINO, I.; BRANCA, T. A.; FORNAI, B.; ROMANIELLO, L.; ROSITO, F. Efficient Use of Water Resources in the Steel Industry. Water, v. 9, n. 11, 2017. https://doi.org/10.3390/w9110874

CONSELHO ESTADUAL DO MEIO AMBIENTE. Resolução n. O2, O2 de fevereiro de 2017. Diário Oficial do Estado, 21 de fevereiro de 2017.

CONCIANI, R. Estudo Comparativo da Mobilidade de Contaminantes Inorgânicos em Solos Laterítico e Não Laterítico. 86 f. Tese (Doutorado em Engenharia Civil e Ambiental) - Departamento de Engenharia Civil e Ambiental, Universidade de Brasília, Brasília, DF, 2016.

DONAGEMA, G. K.; CAMPOS, D. V. B.; CALDERANO, S. B.; TEIXEIRA, W. G.; VOANA, J. H. M. (Orgs.). Manual de Métodos de Análise de Solo. $2^{a}$ ed. Rio de Janeiro: EMBRAPA, 2011.

SANTOS, H. G.; JACOMINE, P. K. T.; ANJOS, L. H. C.; OLIVEIRA, V. A. LUMBRERAS, J. F.; COELHO, M. R.; ALMEIDA, J. A. ARAÚJO FILHO, J. C.; OLIVEIRA, J. B.; CUNHA, T. J. F. Sistema Brasileiro de Classificação de Solos. 5a ed. Brasília: EMBRAPA, 2018

SOBRAL, L. F; BARRETO, M. C. V:; SILVA, A. J.; ANJOS, J. L. Guia prático para interpretação de resultados de análises de solos. Aracaju: EMBRAPA, 2015.13 p.

GENUCHTEN, M. T.; WIERENGA, P. J. Solute dispersion coefficients and retardation factors. In: Methods of soil analysis, Part 1. Madison: American Society of Agronomy - Soil Science Society of America, 1986, p. 1025-1054. https://doi.org/10.2136/sssabookser5.1.2ed

KWIATKOWSKA-MALINA, J. Functions of organic matter in polluted soils: The effect of organic amendments on phytoavailability of heavy metals. Applied Soil Ecology, v. 123, p. 542-545, 2018. https://doi.org/10.1016/j.apsoil.2017.06.021

LUCHESE, A. V:; COSTA, A. C. S.; SOUZA JÚNIOR, I. G. Lixiviação de íons após a aplicação de resíduos orgânicos de uma indústria farmoquímica. Revista Brasileira de Engenharia Agrícola e Ambiental, v. 12, n. 2. 2008, p. 189-199. https://doi.org/10.1590/S1415-43662008000200012
MATOS, A. T. Qualidade do meio físico ambiental. Caderno didático. Associação dos Engenheiros Agrícolas de Minas Gerais. Departamento de Engenharia Agrícola, Universidade Federal de Viçosa. 2010.

MATOS, A. T.; GARIGLIO, H. A. A.; MONACO, P. A.V. L. Deslocamento miscível de cátions provenientes da vinhaça em colunas de solo. Revista Brasileira de Engenharia Agrícola e Ambiental, v. 17, n. 7. p. 743-749, 2013. https://doi org/10.1590/S1415-43662013000700008

MOREIRA, D. A.; MARTINEZ, M. A.; SOUZA, J. A. R.; MATOS, A. T.; REIS, C. BARROS, F. M. Fatores de retardamento e coeficientes de dispersãodifusão de metais pesados em resíduos da construção civil e demolição. Revista Ambiente \& Água, v. 5, n. 2, p. 77-86, 2010. https://doi.org/10.413/ ambi-agua.138

NASCIMENTO, R. S. M. P.; CARVALHO, G. S.; PASSOS, L. P.; MARQUES, J. J. Lixiviação de chumbo e zinco em solo tratado com resíduos de siderurgia. Pesquisa Agropecuária Tropropical, v. 40, n. 4, p. 497-504, 2010. https://doi org/10.1590/S1983-40632010000400001

NIELSEN, D. R.; BIGGAR, J. W. Miscible displacement: III. Theoretical considerations. Soil Science Society of America Proceedings, v. 26, n. 3, p 216-221, 1962. https://doi.org/10.2136/sssaj1962.03615995002600030010x

NYSTRAND, M. I.; ÖSTERHOLM, P.; YUB, C.; ÅSTRÖM, M. Distribution and speciation of metals, phosphorus, sulfate and organic material in brackish estuary water affected by acid sulfate soils. Applied Geochemistry, v. 66, p 264-274, 2016. http://doi.org/10.1016/j.apgeochem.2016.01.003

OLIVEIRA, F. C.; LEMKE-DE-CASTRO, M. L.; RODRIGUES, C.; BORGES, J. D. Adsorção e deslocamento do íon cádmio em solos do cerrado. Revista Brasileira de Engenharia Agrícola e Ambiental, v. 14, n. 8, 2010, p. 848-855. https://doi.org/10.1590/S1415-43662010000800009

OLIVEIRA, L. F. C.; NOGUEIRA, J. G.; FRIZZARIM, S. S.; FIA, R.; FREITAS, J. S.; FIA, F. R. L. Sorção e mobilidade do lítio em solos de áreas de disposição final de resíduos sólidos urbanos. Engenharia Sanitária Ambiental, v. 18, n. 2, p. 139-148, 2013. https://doi.org/10.1590/S141341522013000200006

SANTOS, J. S.; LIMA, V. L. A.; BORGES, J. C. F.; SILVA, L. V. B. D.; AZEVEDO C. A. V. Mobilidade de solutos em colunas de solo com água residuária doméstica e de suinocultura. Revista Brasileira de Engenharia Agrícola e Ambiental, v. 14, n. 11, p. 1226-1233, 2010. https://doi.org/10.1590/S141543662010001100013

SILVA, N. F.; LELIS NETO, J. A.; TEIXEIRA, M. B.; CUNHA, F. N.; MIRANDA, J. H.; COELHO, R. D. Distribuição de solutos em colunas de solo com vinhaça. Irriga - Winotec - Edição Especial, v. 1, n. 1, p. 340-350, 2012. https://doi org/10.15809/irriga.2012v1n01p340

TORETTA, V.; KATSOYIANNIS, I.; COLLIVIGNARELLI, M. C.; BERTANZA, G.; XANTHOPOULOU, M. Water reuse as a secure pathway to deal with water scarcity. MATEC Web of conferences, v. 305, 2020. https://doi.org/10.1051/ matecconf/202030500090

VALOCCHI, A. J. Describing the transport of ion-exchanging contaminants using an effective Kd approach. Water Resources Research, v. 20, p. 499503, 1984. https://doi.org/10.1029/WRO2OI0O4P0O499 